\title{
Contamination tracer testing with seabed drills: IODP Expedition 357
}

\author{
Beth N. Orcutt ${ }^{1}$, Markus Bergenthal ${ }^{2}$, Tim Freudenthal ${ }^{2}$, David Smith ${ }^{3}$, Marvin D. Lilley ${ }^{4}$, \\ Luzie Schnieders $^{2}$, Sophie Green ${ }^{3}$, and Gretchen L. Früh-Green ${ }^{5}$ \\ ${ }^{1}$ Bigelow Laboratory for Ocean Sciences, East Boothbay, ME 04544, USA \\ ${ }^{2}$ MARUM, University of Bremen, 28334 Bremen, Germany \\ ${ }^{3}$ British Geological Survey, The Lyell Centre, Edinburgh, EH14 4AP, Scotland, UK \\ ${ }^{4}$ School of Oceanography, University of Washington, Seattle, WA 98195 , USA \\ ${ }^{5}$ Institute for Geochemistry and Petrology, ETH Zürich, 8092 Zürich, Switzerland
}

Correspondence to: Beth N. Orcutt (borcutt@bigelow.org)

Received: 5 July 2017 - Revised: 18 August 2017 - Accepted: 22 August 2017 - Published: 30 November 2017

\begin{abstract}
IODP Expedition 357 utilized seabed drills for the first time in the history of the ocean drilling program, with the aim of collecting intact sequences of shallow mantle core from the Atlantis Massif to examine serpentinization processes and the deep biosphere. This novel drilling approach required the development of a new remote seafloor system for delivering synthetic tracers during drilling to assess for possible sample contamination. Here, we describe this new tracer delivery system, assess the performance of the system during the expedition, provide an overview of the quality of the core samples collected for deep biosphere investigations based on tracer concentrations, and make recommendations for future applications of the system.
\end{abstract}

\section{Introduction}

IODP Expedition 357 "Atlantis Massif Serpentinization and Life" aimed to collect intact sequences of shallow mantle core for examining serpentinization and deep biosphere processes (Früh-Green et al., 2015, 2016). As such, collection of high-quality core material for geochemical and microbiological analysis was a priority, and methods for assessing the quality of the core material were needed. The use of synthetic tracers in drilling fluids to monitor for potential contamination of drill core samples for microbiological analysis has become fairly routine during microbiology-focused expeditions (Inagaki et al., 2015; Lever et al., 2006, 2013; Smith et al., 2000; Friese et al., 2017; Sauvage et al., 2016). Perfluoromethylcyclohexane (PFC) has been identified as an ideal tracer because of the large range of concentrations that are detectable (i.e., across 6 orders of magnitude) with a gas chromatograph equipped with an electron capture detector (GC-ECD) (Smith et al., 2000; Lever et al., 2006; Sauvage et al., 2016). Recent reports have also demonstrated the use of other fluorescent solutions (Friese et al., 2017; Kallmeyer, 2017). Particulate tracers, such as fluorescent beads, are used less frequently due to problems with dispersion, dilution, and false negatives (Lever et al., 2006; Smith et al., 2000).

During seafloor drilling with a drillship such as the JOIDES Resolution or Chikyu, drilling fluids (muds) are prepared at the sea surface and injected into the drill pipe, and the concentration of PFC tracer delivered into the flush water can be closely monitored and adjusted to reach saturating conditions (roughly $1 \mathrm{mg} \mathrm{L}^{-1}$ ), as described in detail elsewhere (Sauvage et al., 2016; Lever et al., 2006). Similar approaches were also recently used for platform drilling in the relatively shallow waters of the Baltic Sea on IODP Expedition 347, where PFC tracer was added to drilling muds at the platform prior to injection into the borehole (Andrén et al., 2015).

In contrast, seabed drills are remote drilling platforms that directly use bottom seawater as flushing fluid, without addition of muds or fluid connection to the surface (Freudenthal and Wefer, 2007). Therefore, in order to use PFC tracers for contamination testing with seabed drills, a new system was required for delivery of PFC tracer into the drill rig suction line for bottom seawater being injected into the bore- 
hole during seabed drilling (Früh-Green et al., 2017e). Here, we describe such a drill-independent system and how it was used during seabed drilling by two seabed drill systems - the RD2 from the British Geological Survey, and the MARUMMeBo70 from the Center for Marine Environmental Sciences at the University of Bremen (MARUM; Germany) - during IODP Expedition 357 at the Atlantis Massif.

\section{Tracer delivery system}

The seabed drill tracer delivery system was designed to deliver approximately $50 \mu \mathrm{L} \mathrm{min}^{-1}$ of pure PFC solution (Sigma Aldrich) directly into the stream of flushing water to achieve a saturating concentration of $1 \mathrm{mg} \mathrm{L}^{-1}$ for a flushing rate of $50 \mathrm{~L}$ seawater $\mathrm{min}^{-1}$. The system consists of a micro annular gear pump integrated into a filter-pump-valve module with short, direct connections for precise and reproducible dosing (Fig. 1). The pump is driven by an electric motor. The flow rate is controlled by motor speed using an S-BL programmable controller. The tracer fluid is provided within a disposable intravenous solution bag. The ON/OFF $2 / 2$ shift valve is opened when the pump is operated, and closed in off mode to prevent the tracer from accidentally being sucked out of the reservoir in the unlikely case of underpressure in the suction line for flush water. The electronics were housed in a one-atmosphere pressure housing. A system was mounted onto each drill and controlled from the surface via a dedicated RS232 serial communication link to the subsea tracer controller. The tracer solution was injected into the suction line of the drill mud pump. The flow rate of PFC delivery was adjustable from 0.015 to $5 \mathrm{~mL} \mathrm{PFC} \mathrm{min}^{-1}$, and it was set at a fixed rate during each deployment (Table 1). The flushing rate on the rock drills varied throughout operations but tended to range from 20 to $50 \mathrm{~L} \mathrm{~min}^{-1}$.

Pumping rates were initially calculated based on the flush rate of the drill and the required concentration of tracer to be injected into the system. However, subsea trials of the system were not possible prior to the expedition to confirm this functionality. Tests for PFC concentrations on samples obtained from the first holes revealed that the concentrations achieved were below those expected and required (as described below). Accounting for blockages in lines and long flow paths from the pump to the suction pump, pumping rates were increased to try to improve concentrations, without initial success (Table 1). One pump was then taken apart, and the internal rubber paddle, responsible for opening and closing the valve supplying the PFC tracer, was found to have swollen to almost twice the size it should have been, thus blocking supply. To evaluate this situation, a different rubber paddle was immersed in PFC tracer in controlled conditions in the laboratory to see if the swelling was an adverse reaction to the tracer itself, but there was no discernible change in size of the paddle after $24 \mathrm{~h}$. Nevertheless, it is likely that this swelling was a long-term reaction of the valve rubber material in deep-

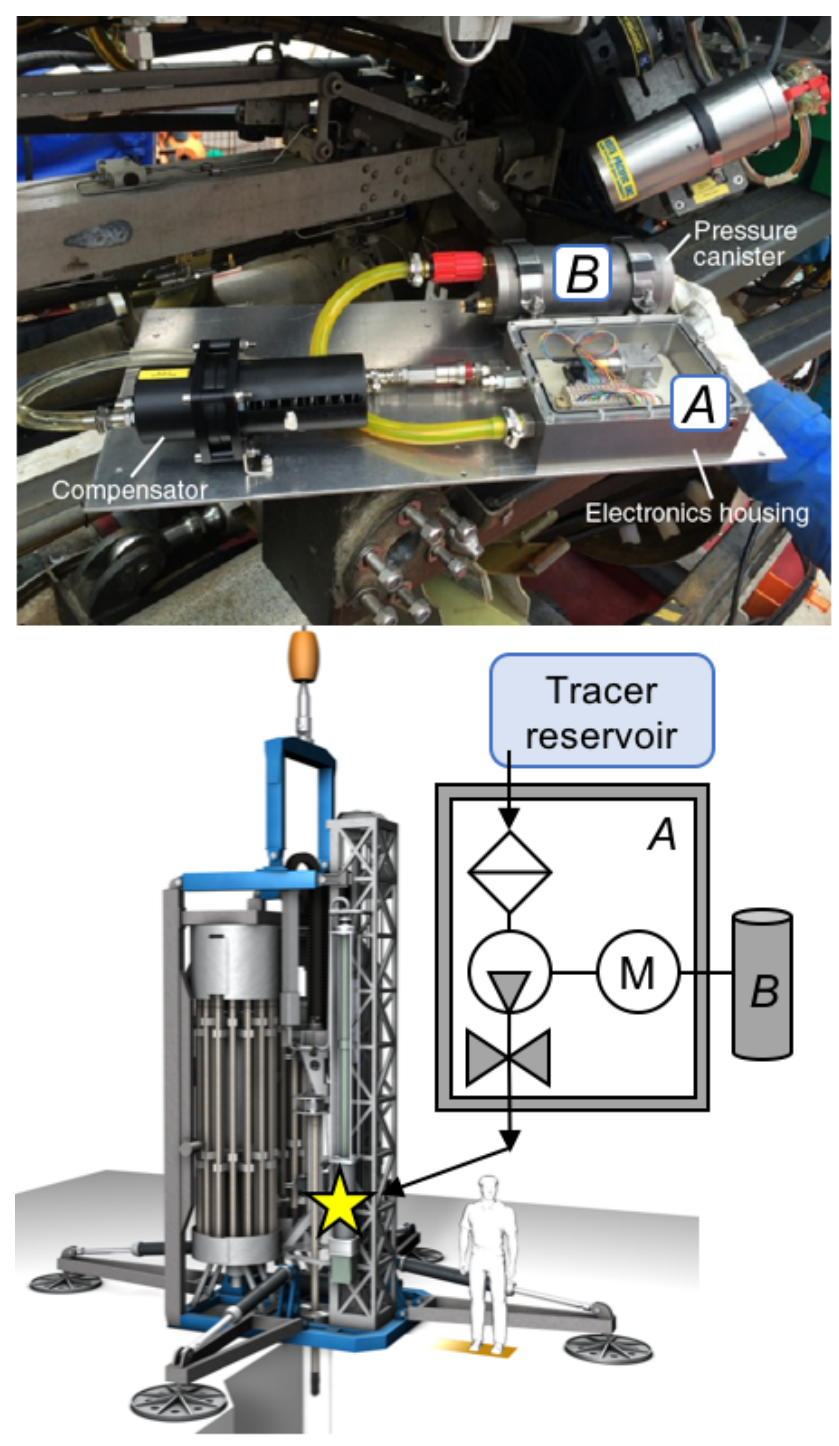

Figure 1. The drill-mounted tracer injection system during IODP Expedition 357. The top panel shows a plate on the MeBo seabed drill with the filter-pump-valve (F-P-V) module (A) in an electronics housing, pressure canister with micromotor controller (B), and oil compensator. The lower panel shows a schematic of the tracer system as mounted on the MeBo drill rig. A flexible bag with a tracer was connected to the F-P-V (A), with pumping controlled by the motor (B), to deliver the tracer to the suction and mixing chamber (star) for mixing with bottom seawater before being injected into the borehole via a displacement pump. Top panel image courtesy of Tim Freudenthal, and reproduced from Fig. F17 in Früh-Green et al. (2017e) with permission.

sea contact with either the tracer or seawater. Since the valve was only added as a safety measure to prevent uncontrolled loss of tracer during off-mode of the tracer pump, the paddle was shaved to reduce its size and allow the valve to be left in the permanently open position. Concentrations in fluid samples acquired after these changes were much improved, and 
Table 1. Summary of PFC tracer system operations during IODP Expedition 357 organized by hole, including water depth in meters, drilling sequence order, drill rig, speed of delivery pump (revolutions per minute) and laboratory lower detection limits (in pg $\mathrm{cm}^{-3}$ ) for the quantification method. ${ }^{a}$ by drilling order number indicates deployments after the tracer delivery pump modification as described in the text. Two different detection limits for Hole $71 \mathrm{C}$ samples (indicated by ${ }^{b}$ ) indicates two different labs where samples were collected, with the lower value indicating the blank for the lab where sensor package and liner fluid samples were collected. Pump speeds previously reported elsewhere (Früh-Green et al., 2017e).

\begin{tabular}{llllll}
\hline Hole & Water depth $(\mathrm{m})$ & Drilling order & Drill rig & Pump speed & Detection limit \\
\hline 68A & 1103 & 1 & RD2 & 50 & 0 \\
68B & 1102 & $13^{\mathrm{a}}$ & RD2 & 100 & 75 \\
69A & 851 & 2 & RD2 & 50 & 0 \\
$70 \mathrm{~A}$ & 1141 & 3 & MeBo & 55 & 0 \\
$70 \mathrm{~B}$ & 1141 & 7 & RD2 & 1500 & 15 \\
$70 \mathrm{C}$ & 1141 & $12^{\mathrm{a}}$ & MeBo & 100 & 30 \\
$71 \mathrm{~A}$ & 1391 & 4 & MeBo & 55 & 20 \\
$71 \mathrm{~B}$ & 1380 & 11 & RD2 & 1500 & 25 \\
$71 \mathrm{C}$ & 1390 & $14^{\mathrm{a}}$ & MeBo & 50 & $75 / 500^{\mathrm{b}}$ \\
$72 \mathrm{~A}$ & 820 & 5 & RD2 & 100 & 20 \\
$72 \mathrm{~B}$ & 820 & 6 & RD2 & 100 & 15 \\
$73 \mathrm{~A}$ & 1430 & 8 & MeBo & 1500 & 15 \\
$74 \mathrm{~A}$ & 1550 & $17^{\mathrm{a}}$ & MeBo & 50 & 85 \\
$75 \mathrm{~A}$ & 1568 & $15^{\mathrm{a}}$ & RD2 & 50 & 75 \\
$75 \mathrm{~B}$ & 1568 & $16^{\mathrm{a}}$ & RD2 & 50 & 85 \\
$76 \mathrm{~A}$ & 768 & 9 & RD2 & 1500 & 15 \\
$76 \mathrm{~B}$ & 768 & 10 & RD2 & 1500 & 15 \\
\hline
\end{tabular}

pumping rates for tracer injection were thus reduced to the calculated values (Table 1).

\section{Tracer monitoring, sample collection, and analysis}

To monitor PFC delivery during drilling operations, a variety of samples were collected from the seabed drills after drilling: core liner fluid samples, sensor package Niskin bottle samples, and exterior and interior core samples, as described in detail elsewhere (Früh-Green et al., 2017e). The sample type referred to as "liner fluid" represents a mixture of bottom water that was in the core barrel prior to being replaced by core, as well as flushing water entrained during coring. Liner fluids were collected outside on the ship deck by draining fluid from the ball valve at the top of the core prior to opening the core barrel to recover the core inside, or by draining at the lower end of the core before removing the core liner from the core barrel. In both cases, fluids were collected into a sterile $50 \mathrm{~mL}$ centrifuge tube, and then $10 \mathrm{~mL}$ of this fluid was immediately transferred to a $22 \mathrm{~mL}$ glass headspace vial and crimp sealed. For sensor package "Niskin water" samples, $10 \mathrm{~mL}$ fluid samples were collected from each of three drill-mounted Niskin bottles, which sampled the fluids flushed out of the borehole near the breakout table and bottom seawater, as described elsewhere (FrühGreen et al., 2017e). However, it is important to note that these fluid samples were often collected minutes to hours after active drilling (and flushing of the borehole) ended, so the samples likely represented a lower end-member of tracer concentration. For shipboard core samples, when cores were transferred to the shipboard laboratory to select whole-round cores for ephemeral microbiological analyses (Früh-Green et al., 2017e), $1-5 \mathrm{~cm}^{3}$ of core in the form of small fragments was transferred to $22 \mathrm{~mL}$ glass headspace vials containing $5 \mathrm{~mL}$ of distilled water and crimp sealed. These represented the "exterior" of the core. After flame-sterilization of the exterior surface whole-round core pieces (following the principle described elsewhere, Lever et al., 2006), "interior" samples for PFC analysis were collected in a similar manner using a flame-sterilized hammer and chisel to generate fragments from the interior of the flamed whole-round core piece. Care was taken to conduct the flame-sterilization step (which would volatilize the PFC tracer into the laboratory atmosphere) in a separate laboratory from where the samples were prepared and measured, to minimize the risk of false positives.

After shipboard collection of the above samples, the exteriors of the crimped headspace vials were rinsed with copious amounts of water, dried, and heated in a $70^{\circ} \mathrm{C}$ oven for several hours prior to analysis. At the same time, a set of PFC standards was prepared under a fume hood in the same type of vial and also heated in the oven, following established tracer dilution protocols (Smith et al., 2000). It is important to note that the fume hood on the RRS James Cook vented into the laboratory after passing through a charcoal filter (i.e., it did not vent to the exterior of the ship), and both the oven and the GC-ECD used for analysis also vented into the room; this led to a small buildup of PFC tracer in the atmosphere of 
the analysis laboratory over time. Care was taken to conduct thorough analysis of the atmospheric concentration of PFC tracer in all laboratories during analyses, both from air samples collected directly into syringes during GC-ECD analysis and from headspace vials closed in the laboratories during sample collection, to account for the possibility of false positives.

Shipboard PFC tracer analysis followed established protocols (Smith et al., 2000; Lever et al., 2006; Sauvage et al., 2016). Using a heated $\left(70^{\circ} \mathrm{C}\right)$ disposable plastic $3 \mathrm{~mL}$ syringe fitted with a two-way stopcock and a $51 \mathrm{~mm}, 22$-gauge Hamilton needle, a $2 \mathrm{~mL}$ headspace sample from either sample or standard vials was injected into the splitless injector on Agilent 7890A GC system GC-ECD, kindly provided by Douglas Connelly of the University of Southampton. The GC-ECD was equipped with a $30 \mathrm{~m}$ length $\times 53 \mu \mathrm{m}$ inner diameter $\times 15 \mu \mathrm{m}$ coating thickness Agilent HP-AL/M column run with ultrahigh-purity nitrogen carrier gas at $4.7 \mathrm{psi}$ $\left(57 \mathrm{~mL} \mathrm{~min}^{-1}\right)$ with an initial column temperature of $120^{\circ} \mathrm{C}$ for $0.5 \mathrm{~min}$, followed by a $50^{\circ} \mathrm{C} \mathrm{min}{ }^{-1} \operatorname{ramp}$ to $200^{\circ} \mathrm{C}$ for $2.2 \mathrm{~min}$. The injector temperature was set at $175^{\circ} \mathrm{C}$. Under these parameters, the PFC peak eluted at roughly $3.4 \mathrm{~min}$ as monitored with Agilent ChemStation Rev B.03.03 software. The concentrations of PFC tracer in samples were determined by comparing the peak area to a standard curve of peak area versus PFC tracer injected from the standards. Based on duplicate analysis of standards, the limit of detection was $2 \times 10^{-12} \mathrm{~g}(2 \mathrm{pg}) \mathrm{PFC}$, which is in the range of what was determined previously (Smith et al., 2000; Lever et al., 2006). Samples collected throughout the expedition were measured shipboard in batches against the same standard calibration curves. Laboratory atmosphere blanks are also reported to define lower detection limits; these values varied throughout the expedition due to buildup of volatilized tracer in the shipboard laboratory. Because of the variability in tracer pump delivery, it was not possible to convert PFC concentrations observed in the samples into the volume of flushing water potentially contaminating the core, as is commonly done. For this expedition, concentrations are reported simply as the amount of PFC tracer per volume, with PFC concentrations for samples reported in picograms PFC per cubic centimeter of sample and laboratory blanks reported as picograms PFC per milliliter air (Table 1).

In addition to shipboard assessment of tracer concentrations, frozen core samples collected for deep biosphere investigation were further subsampled for PFC tracer levels several weeks after the end of the shipboard work in shorebased laboratories (at the Kochi Core Center, Kochi, Japan, and at the Bigelow Laboratory for Ocean Sciences, Maine, USA). In some cases, the exterior of the core sample had been flame sterilized on the ship prior to freezing. Depending on the quality of the frozen core sample (i.e., an intact core whole-round versus rubbly, broken pieces), the core was treated as follows: (1) if intact, the exterior of the core sample was removed via a steam-sterilized band saw

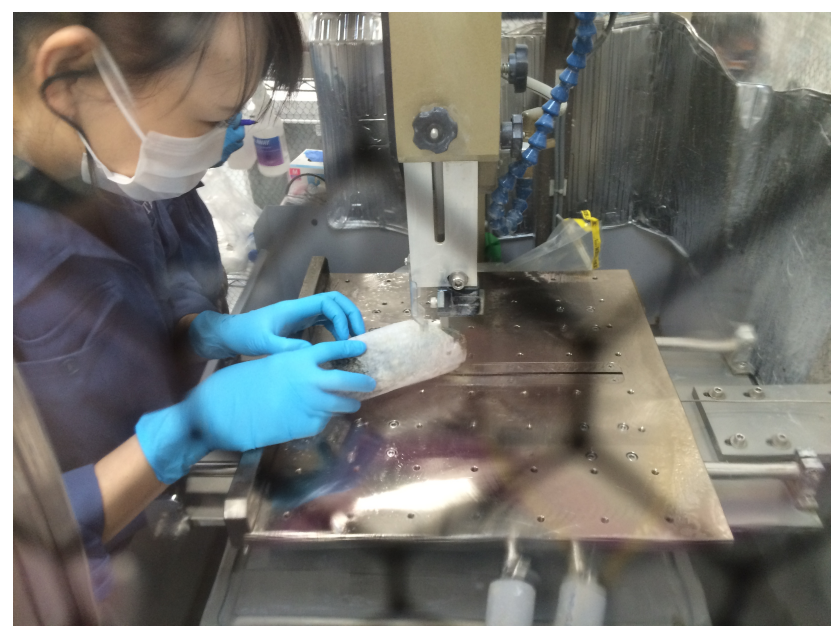

Figure 2. Example of cutting of a frozen whole-round core sample with the ultraclean diamond band saw with frozen stage inside a filtered air clean booth, available at the Kochi Core Center. Photograph by Beth Orcutt.

on a frozen stage (Fig. 2), generating "exterior" and "interior" fractions of the frozen core that were then subsampled; and (2) if rubbly, the core pieces were serially rinsed 10 times in ultrapure water within a combusted glass container. For the exterior fraction, roughly $1 \mathrm{~cm}^{3}$ of rock was transferred directly to a glass headspace vial with $5 \mathrm{~mL}$ water and crimp sealed. For the interior and rinsed fractions, the entire sample was first homogenized into a sand using autoclaved and/or flame-sterilized stainless-steel chisels, plates, percussion mortars, mortars, pestles, and spatulas while working between a $\mathrm{KOACH}$ benchtop laminar flow system (Fig. 3), and then approximately 1-2 g of sand-sized powder was transferred to a glass headspace vial with $5 \mathrm{~mL}$ of water and crimp sealed. It is important to note that all sample processing, as well as steam- and flame-sterilization of implements, occurred in the same laboratory, which lead to a buildup in ambient PFC concentrations in the atmosphere as assessed by collection of regular laboratory air blank samples. All of the frozen core subsamples were analyzed on a Shimadzu GC-17A system GC-ECD with a splitless injector, kindly provided by Steven D'Hondt at the University of Rhode Island Graduate School of Oceanography, following methods described elsewhere (Sauvage et al., 2016). The GC-ECD was equipped with a $15 \mathrm{~m}$ length $\times 53 \mu \mathrm{m}$ inner diameter $\times 15 \mu \mathrm{m}$ coating thickness HP PLOT Al/M column run with ultrahigh-purity nitrogen carrier gas at $30 \mathrm{~mL} \mathrm{~min}^{-1}$ with an initial column temperature of $120^{\circ} \mathrm{C}$ for $3.0 \mathrm{~min}$, followed by a $20^{\circ} \mathrm{C} \mathrm{min}^{-1}$ ramp to $150^{\circ} \mathrm{C}$ and held for $1 \mathrm{~min}$. The ECD injector and detector temperatures were 185 and $195^{\circ} \mathrm{C}$, respectively. Vials were heated prior to injection for at least $30 \mathrm{~min}$ at $70^{\circ} \mathrm{C}$. As there was no discernable trend in the concentration of PFC in the blank samples, the limit of detection for these batches of samples were determined from 


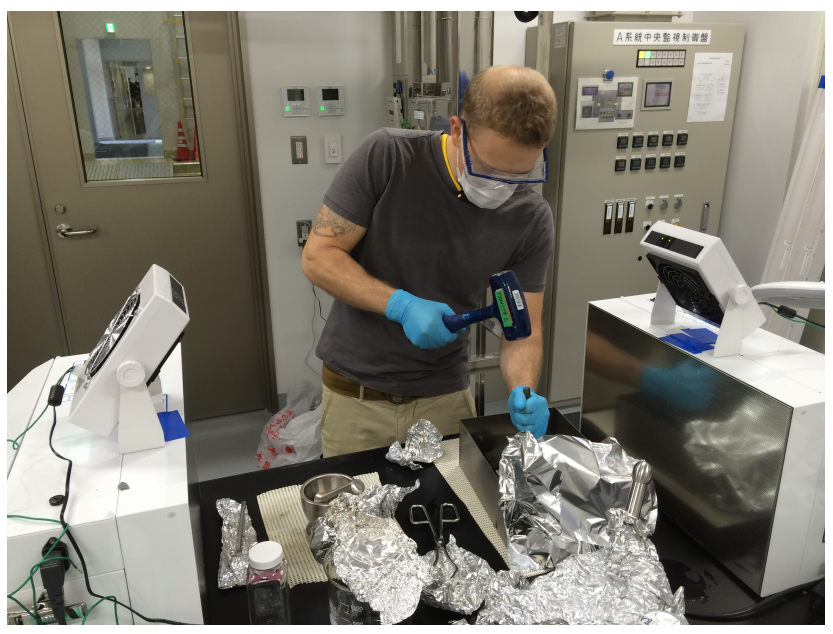

Figure 3. Example of sample homogenization within the $\mathrm{KOACH}$ benchtop laminar flow system at the Kochi Core Center. Photograph by Beth Orcutt.

the averages of the laboratory blanks, which ranged from 10 to $1000 \mathrm{pg}$ PFC per $\mathrm{cm}^{3}$ air, depending on the laboratory.

\section{Assessment of tracer delivery}

Shipboard analysis of PFC tracer concentrations in core liner fluids and water samples collected with seabed drillmounted Niskin bottles from the seabed drill breakout tables revealed variable success in achieving saturating PFC tracer concentrations, as documented elsewhere (Früh-Green et al., 2017a). Figure 4 provides a representative example of tracer concentrations measured in samples from Hole M0068B; similar data for other Expedition 357 holes are provided in the Supplement (Supplement Figs. S1-S16). During drilling operations at the first dozen holes, PFC delivery as measured in the fluid samples was generally low, with concentrations ranging from below the detection limit to hundreds of picograms of PFC per $\mathrm{cm}^{3}$. The exceptions to this were the deployments at holes M0070A and B (Supplement Figs. S4 and S5), which achieved higher concentrations of thousands of picograms of $\mathrm{PFC} \mathrm{cm} \mathrm{cm}^{-3}$. Prior to the twelfth drill deployment, the tracer delivery pump internal mechanism was repaired as described above, and the subsequent tracer concentrations in the fluid samples increased by orders of magnitude. In some cases, PFC tracer was saturated in the recovered fluid samples (i.e., Hole 75B; Supplement Fig. S14). As these fluid samples represent a mixture of fluids flushed out of the borehole as well as bottom seawater, these concentrations should be viewed as lower estimates of the actual concentration of tracer in the flush waters.

Volumetric PFC concentrations on the rock samples were generally equal to or higher than the concentrations in the water samples (Fig. 4, Supplement Figs. S1-S16). High PFC concentrations were observed on exterior rock sam-

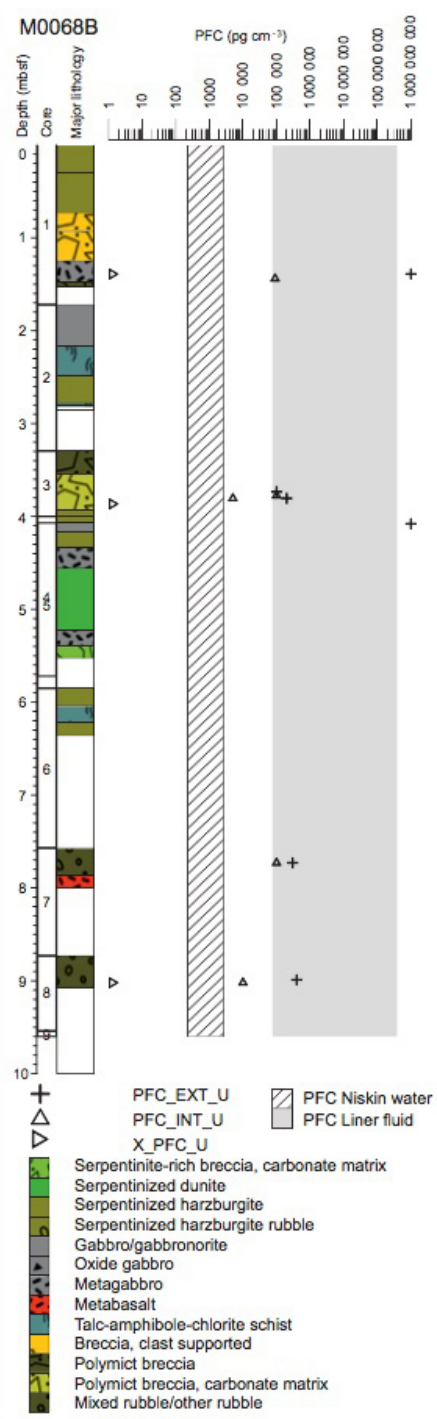

Figure 4. Summary of PFC tracer concentrations (in $\mathrm{pg} \mathrm{cm}^{-3}$ on logarithmic scale) in samples collected during IODP Expedition 357 from Hole M0068B, as compared to the lithology logs from the site according to legend (Früh-Green et al., 2017a). For this figure (and all figures in the Supplement), symbols are as follows. PFC concentrations measured in fluid samples from the sensor package Niskin bottles ("PFC Niskin water", grey shaded box) and the core liner fluids ("PFC Liner fluid", match mark box) presented as the range of lower and upper concentrations measured in samples from each hole. PFC concentrations measured on wholeround core (WRC) samples: PFC_EXT_U (cross), exterior piece of unflamed whole-round core sample (WRC); PFC_INT_U (triangle), interior piece of unflamed WRC; X_PFC_U (arrow), homogenized unflamed WRC after serial rinsing with ultrapure water; PFC_EXT_F (circle), exterior piece of flamed WRC; PFC_INT_F (diamond), interior piece of flamed WRC; X_PFC_F (star), homogenized flamed WRC after serial rinsing with ultrapure water. Values on right-most edge of axis represent values above the maximum detection limit $\left(>1 \mathrm{mg} \mathrm{cm}^{-3}\right)$, and values on left-most edge of axis represent values below the minimum detection limit (as shown in Table 1). 
ples from holes M0068B (Fig. 4), M0070A/B/C (Supplement Figs. S4-S6), M0071A/B/C (Supplement Figs. S7-S9), M0075A/B (Supplement Figs. S13-S14), and M0076A/B (Supplement Figs. S15-S16). Exterior rock samples from holes M0069A (Supplement Fig. S3) and M0072A/B (Supplement Figs. S10-S11) were generally lower in PFC concentration. PFC concentrations in the one sediment core collected from M0074A were low (Supplement Fig. S12). Core samples were not collected from Hole M0073A (no core recovery).

\section{Assessment of sample quality for deep biosphere investigations}

The primary motivation for designing the tracer delivery system was to enable assessment of the quality of the core samples for deep biosphere investigations, and the degree to which samples might be compromised by exposure to bottom seawater or other sources. Various strategies were employed during the expedition to assess the intrusion of tracer into the interior of the core samples, including flaming of the exterior of the whole-round core with a handheld butane torch (to volatilize the PFC tracer on the exterior of the core, and presumably destroy any contaminating microbial cells), and/or physical removal of the exterior of the core with a diamond-tipped band saw (Fig. 2), and or serial rinsing of the core exterior with distilled water. Given the variable nature of the core recovered, which ranged from coherent pieces to rubble (Früh-Green et al., 2016), these strategies had varying degrees of success. Interior core samples from Hole M0068B still had high PFC concentrations, even after flaming or physical removal of the core exteriors (Fig. 4), which was expected given the very crumbly and talc-rich nature of the serpentinized samples from this core (Früh-Green et al., 2017a). By comparison, serial rinsing of whole-round cores from this hole with ultrapure water resulted in very low PFC concentrations (Fig. 4). Interior core pieces from Site M0070 holes often had lower PFC concentrations than in the exterior samples (Supplement Figs. S4-S6), suggesting limited intrusion of the tracer into the basalt breccias at this site (Früh-Green et al., 2017c). Flaming of the core material from Site M0071 was generally effective at preventing PFC intrusion into the interior of the core samples (Supplement Figs. S8-S10), which was expected considering that many of these samples were coherent (Früh-Green et al., 2017d). Site M0075 samples were very rubbly (Früh-Green et al., 2017d), and interior PFC concentrations were generally elevated while washing again seemed to have a positive effect (Supplement Figs. S13-S14). Although core samples from Site M0076 tended to be coherent, they were often rich in veins (Früh-Green et al., 2017b), which likely allowed transfer of PFC into the interiors of some samples (Supplement Figs. S15-S16).

\section{Conclusions}

Overall, the principle and implementation of a tracer injection system for seabed drill systems were proven to work. Following shipboard modification of the designed system, saturating concentrations of perfluoromethylcyclohexane were achievable in the drilling fluids used by the seabed drills during IODP Expedition 357, and PFC concentrations on the exterior and interior of core samples could be used as a measure to assess the quality of the sample material for detailed microbiological and geochemical analyses. With further minor developments, the system would be a reliable for use with any subsea system that required a controllable, low volume fluid injection system. One tempting new alterative for core contamination testing is the use of aqueous fluorescent particles as drill fluid tracers, which are cheaper and easier to quantify as compared to the volatile PFC tracer used in this study (Friese et al., 2017; Kallmeyer, 2017).

Data availability. PFC concentration data are provided in the Supplement. Supplement Table S1 details the concentrations in the rock samples, and Supplement Table S2 details the minimum and maximum concentrations in the fluid samples. Data are plotted by hole in Supplement Figs. S1-S16.

\section{The Supplement related to this article is available online at https://doi.org/10.5194/sd-23-39-2017-supplement.}

Author contributions. MB designed and built the tracer delivery system with input from TF, BNO, and DS; MB, TF, and LS deployed the system at sea with input from DS; BNO analyzed all samples with setup support from ML and LS; SG prepared figures; BNO wrote the manuscript with input from all coauthors.

Competing interests. The authors declare that they have no conflict of interest.

Acknowledgements. This technical effort benefited greatly from the advice and support of many individuals before, after, and during the expedition. Steven D'Hondt, Dennis Graham, and Mark Lever provided excellent guidance and advisement during the planning stages. Douglas Connelly and Kate Peel (University of Southampton), Dennis Graham and Steven D'Hondt (University of Rhode Island), and Tamara Baumberger, Rolf Pedersen, and Ingunn Thorseth (University of Bergen) generously provided equipment support and training. The Rock Drill 2 and MeBo Seafloor Drill Rig teams provided expert rig operations and tracer system interface, with support from Dave Smith and Carol Cotterill. Shipboard scientists Susan Lang, Yuki Morono, Marianne Quemeneur, Matthew Schrenk, and Katrina Twing graciously assisted with sample collection, and Gaye Bayrakci, Carol Cotterill, 
Holger Kuhlmann, Sally Morgan, Alex Wülbers, and Ursula Röhl provided additional expedition support. Shorebased sampling was tirelessly provided by William Brazelton, Katherine Hickok, Susan Lang, Yuki Morono, Christopher Thornton, and Nan Xiao with support from Fumio Inagaki and JAMSTEC. We humbly thank the Expedition 357 core description team for tirelessly providing the data for the lithology logs. We thank Katrina Twing for comments on an earlier draft, and Susan Lang for advice on figures. This research used samples and data provided by the International Ocean Discovery Program (IODP). Funding for this work was provided by the US Science Support Program to the IODP (NSF award OCE-1450528, subaward 16(GG009393-01) to BNO), the European Consortium for Ocean Research Drilling (ECORD), and the Deep Carbon Observatory funded by the Alfred P. Sloan Foundation (Sloan-G-2015-14084-Deep Life Community subaward to BNO).

Edited by: Jan Behrmann

Reviewed by: two anonymous referees

\section{References}

Andrén, T., Jørgensen, B. B., Cotterill, C., Green, S., Andrén, E., Ash, J., Bauersachs, T., Cragg, B. A., Fanget, A.-S., Fehr, A., Granoszewski, W., Groeneveld, J., Hardisty, D., HerreroBervera, E., Hyttinen, O., Jensen, J. B., Johnson, S., Kenzler, M., Kotilainen, A., Kotthoff, U., Marshall, I. P. G., Martin, E., Obrochta, S., Passchier, S., Quintana Krupinski, N., Riedinger, N., Slomp, C. P., Snowball, I., Stepanova, A., Strano, S., Torti, A., Warnock, J., Xiao, N., and Zhang, R.: Methods, in: Proc. IODP, 347, edited by: Andrén, T., Jørgensen, B. B., Cotterill, C., Green, S., and Expedition 347 Scientists, Integrated Ocean Drilling Program, College Station, TX, 2015.

Freudenthal, T. and Wefer, G.: Scientific Drilling with the Sea Floor Drill Rig MeBo, Sci. Dril., 5, 63-66, https://doi.org/10.2204/iodp.sd.5.11.2007, 2007.

Friese, A., Kallmeyer, J., Kitte, J. A., Montaño Martínez, I., Bijaksana, S., Wagner, D., The ICDP Lake Chalco Drilling Science Team, and The ICDP Towuti Drilling Science Team: A simple and inexpensive technique for assessing contamination during drilling operations, Limnol. Oceanogr. Methods, 15, 200-211, https://doi.org/10.1002/lom3.10159, 2017.

Früh-Green, G., Orcutt, B. N., Green, S. L., Cotterill, C., Morgan, S., Akizawa, N., Bayrakci, G., Behrmann, J.-H., Boschi, C., Brazelton, W. J., Cannat, M., Dunkel, K. G., Escartín, J., Harris, M., Herrero-Bervera, E., Hesse, K., John, B. E., Lang, S. Q., Lilley, M. D., Liu, H. Q., Mayhew, L. E., McCaig, A. M., Menez, B., Morono, Y., Quéméneur, M., Rouméjon, S., Sandaruwan Ratnayake, A., Schrenk, M. O., Schwarzenbach, E. M., Twing, K., Weis, D., Whattham, S. A., Williams, M., and Zhao, R.: Eastern sites, in: Atlantis Massif Serpentinization and Life. Proceedings of the International Ocean Discovery Program, 357, edited by: Früh-Green, G. L., Orcutt, B. N., Green, S. L., Cotterill, C., and Scientists, E., International Ocean Discovery Program, College Station, TX, 2017a.

Früh-Green, G., Orcutt, B. N., Green, S. L., Cotterill, C., Morgan, S., Akizawa, N., Bayrakci, G., Behrmann, J.-H., Boschi, C., Brazelton, W. J., Cannat, M., Dunkel, K. G., Escartín, J., Harris,
M., Herrero-Bervera, E., Hesse, K., John, B. E., Lang, S. Q., Lilley, M. D., Liu, H. Q., Mayhew, L. E., McCaig, A. M., Menez, B., Morono, Y., Quéméneur, M., Rouméjon, S., Sandaruwan Ratnayake, A., Schrenk, M. O., Schwarzenbach, E. M., Twing, K., Weis, D., Whattham, S. A., Williams, M., and Zhao, R.: Central sites, in: Atlantis Massif Serpentinization and Life. Proceedings of the International Ocean Discovery Program, 357, edited by: Früh-Green, G. L., Orcutt, B. N., Green, S. L., Cotterill, C., and Scientists, E., International Ocean Discovery Program, College Station, TX, 2017b.

Früh-Green, G., Orcutt, B. N., Green, S. L., Cotterill, C., Morgan, S., Akizawa, N., Bayrakci, G., Behrmann, J.-H., Boschi, C., Brazelton, W. J., Cannat, M., Dunkel, K. G., Escartín, J., Harris, M., Herrero-Bervera, E., Hesse, K., John, B. E., Lang, S. Q., Lilley, M. D., Liu, H. Q., Mayhew, L. E., McCaig, A. M., Menez, B., Morono, Y., Quéméneur, M., Rouméjon, S., Sandaruwan Ratnayake, A., Schrenk, M. O., Schwarzenbach, E. M., Twing, K., Weis, D., Whattham, S. A., Williams, M., and Zhao, R.: Northern sites, in: Atlantis Massif Serpentinization and Life. Proceedings of the International Ocean Discovery Program, 357, edited by: Früh-Green, G. L., Orcutt, B. N., Green, S. L., Cotterill, C., and Scientists, E., International Ocean Discovery Program, College Station, TX, 2017c.

Früh-Green, G., Orcutt, B. N., Green, S. L., Cotterill, C., Morgan, S., Akizawa, N., Bayrakci, G., Behrmann, J.-H., Boschi, C., Brazelton, W. J., Cannat, M., Dunkel, K. G., Escartín, J., Harris, M., Herrero-Bervera, E., Hesse, K., John, B. E., Lang, S. Q., Lilley, M. D., Liu, H. Q., Mayhew, L. E., McCaig, A. M., Menez, B., Morono, Y., Quéméneur, M., Rouméjon, S., Sandaruwan Ratnayake, A., Schrenk, M. O., Schwarzenbach, E. M., Twing, K., Weis, D., Whattham, S. A., Williams, M., and Zhao, R.: Western sites, in: Atlantis Massif Serpentinization and Life. Proceedings of the International Ocean Discovery Program, 357, edited by: Früh-Green, G. L., Orcutt, B. N., Green, S. L., Cotterill, C., and Scientists, E., International Ocean Discovery Program, College Station, TX, 2017d.

Früh-Green, G., Orcutt, B. N., Green, S. L., Cotterill, C., Morgan, S., Akizawa, N., Bayrakci, G., Behrmann, J.-H., Boschi, C., Brazelton, W. J., Cannat, M., Dunkel, K. G., Escartín, J., Harris, M., Herrero-Bervera, E., Hesse, K., John, B. E., Lang, S. Q., Lilley, M. D., Liu, H. Q., Mayhew, L. E., McCaig, A. M., Menez, B., Morono, Y., Quéméneur, M., Rouméjon, S., Sandaruwan Ratnayake, A., Schrenk, M. O., Schwarzenbach, E. M., Twing, K., Weis, D., Whattham, S. A., Williams, M., and Zhao, R.: Expedition 357 methods, in: Atlantis Massif Serpentinization and Life, Proceedings of the International Ocean Discovery Program, 357, edited by: Früh-Green, G., Orcutt, B. N., Green, S. L., Cotterill, C., and Scientists, T. E., International Ocean Discovery Program, College Station, TX, 2017e.

Früh-Green, G. L., Orcutt, B. N., and Green, S.: Expedition 357 Scientific Prospectus: Atlantis Massif Serpentinization and Life, International Ocean Discovery Program (IODP), 357, https://doi.org/10.14379/iodp.sp.357.2015, 2015.

Früh-Green, G. L., Orcutt, B. N., Green, S., Cotterill, C., and Expedition 357 Scientists: Expedition 357 Preliminary Report: Atlantis Massif Serpentinization and Life, International Ocean Discovery Program, 2016.

Inagaki, F., Hinrichs, K. U., Kubo, Y., Bowles, M. W., Heuer, V. B., Hong, W. L., Hoshino, T., Ijiri, A., Imachi, H., Ito, M., Kaneko, 
M., Lever, M. A., Lin, Y.-S., Methé, B., Morita, S., Morono, Y., Tanikawa, W., Bihan, M., Bowden, S. A., Elvert, M., Glombitza, C., Gross, D., Harrington, G. J., Hori, T., Li, K., Limmer, D., Liu, C.-H., Murayama, M., Ohkouchi, N., Ono, S., Park, Y.-S., Philips, S. C., Prieto Mollar, X., Purkey, M., Riedinger, N., Sanada, Y., Sauvage, J., Snyder, G., Susilawati, R., Takano, Y., Tasumi, E., Terada, T., Tomaru, H., Trembath-Reichert, E., Wang, D. T., and Yamada, Y.: Exploring deep microbial life in coal-bearing sediment down to $\sim 2.5 \mathrm{~km}$ below the ocean floor, Science, 349, 420-424, 2015.

Kallmeyer, J.: Contamination control for scientific drilling operations, in: Advances in Applied Microbiology, edited by: Sariaslani, S. and Gadd, G. M., Elsevier, Cambridge, San Diego, London, Oxford, 61-92, 2017.

Lever, M., Alperin, M. J., Engelen, B., Inagaki, F., Nakagawa, S., Steinsbu, B. O., Teske, A., and Scientists, I. E.: Trends in basalt and sediment core contamination during IODP Expedition 301, Geomicrobiol. J., 23, 517-530, 2006.
Lever, M. A., Rouxel, O. J., Alt, J. C., Shimizu, N., Ono, S., Coggon, R. M., Shanks III, W. C., Lapham, L., Elvert, M., Prieto Mollar, X., Hinrichs, K. U., Inagaki, F., and Teske, A.: Evidence for microbial carbon and sulfur cycling in deeply buried ridge flank basalt, Science, 339, 1305-1308, 2013.

Sauvage, J., Lewis, L., Graham, D., Spivack, A. J., and D'Hondt, S.: Data report: quantification of potential drilling contamination using perfluorocarbon tracer at IODP Expedition 329 sites, in: Proceedings of the Integrated Ocean Drilling Program, 329, edited by: D'Hon, Inagaki, F., Alvarez Zarikian, C. A., and Scientists, E., Integrated Ocean Drilling Program Management International, Inc., Tokyo, 2016.

Smith, D. C., Spivack, A. J., Fisk, M. R., Haveman, S. A., Staudigel, H., and Party, L. S. S.: Methods for quantifying potential microbial contamination during deep ocean coring, ODP Technical Note, 28, https://doi.org/10.2973/odp.tn.28.2000, 2000. 